species has useful outline diagrams of many of them against a profile of a river and of a lake. The central section begins with a key to the main groups of fishes, based on body shape and on types and arrangements of fins. There are two pages each of text and pictures of important food animals at the beginning; twelve further pages at the end of the section are devoted to crayfish, the mitten crab, the pearl mussel and fish predators and parasites. The 130 species of fish are described in 142 pages with many delightful illustrations, including small colour pictures of principal food items for nearly every fish species and sometimes also colour pictures of young stages, predators, plants or fishing lures. There are keys to the species within large families such as the salmon and carp families. The descriptions of the individual species include information about size, habitat, feeding habits, spawning habits and value to man, if any.

It is a pity that the book is marred by occasional errors, such as, for instance, a confusion of the captions associated with the diagrams of swimbladder arrangements of perch and herring and, more serious, the omission of asterisks in the key to the carp family to indicate that the following species occur in Britain: dace, roach, minnow, bitterling (introduced), bleak, bream and white bream. In spite of these and other mistakes, however, it is highly recommended. The text includes a wealth of information and the illustrations are not only helpful but so beautiful that it is a pleasure simply to thumb through looking at the pictures.

M.E. VARLEY

\title{
The Palaearctic-African Bird Migration Systems, by R. E. Moreau. Academic Press, $£ 7.80$.
}

This is an important scientific book, and, as it deals with movements and ecology, one with lessons for conservation. It is a posthumous publication, the distinguished author having died in 1970 after devoting the last years of his life, under the handicap of severe illness, to collecting facts for it from a wide spectrum of literature and from numerous correspondents; and all this was based on his own extensive knowledge of African conditions and the native birdlife, subject of an earlier work. Until near the end, his hospital bed was deep in papers as he struggled to complete his task; even so, the book still needed skilful editing by his literary executor, Dr J. F. Monk.

The volume includes a massive presentation of data, species by species, but here it is possible only to highlight a few points in the more general chapters. It is estimated that about 3750 million migrants from the Palaearctic Region spend the northern winter in Africa south of the Sahara, and a major problem is how this vast extra population is supported. The majority do not cross the equator, and their stay in the northern tropics roughly coincides with the dry season and a deteriorating food situation. In the southern tropics, where the seasons are reversed, food is more abundant but there is greater competition by the native birds then breeding.

The migrants come to Africa not only from Europe but also from Asia; in the latter an initially westward flight avoids the barrier of the Tibetan plateau and the Himalayas, which few cross and only a minority circumvent. Even where the movement is mainly southwards, from Europe, there are the formidable barriers of the Mediterranean and the Sahara, sometimes both crossed in a single prodigious flight.

There is increasing evidence of the recurrence of individuals at the same wintering sites in successive years, and also replication of intratropical winter movements; some of these last, incidentally, have the classic form of nocturnal migration. The whole system shows substantial regularity, and yet the history of climatic change requires that the present pattern must have 
evolved within no more than a few thousand years.

The whole is a fitting monument to the author's erudition, industry and gift for integrating complex evidence of different kinds; it is thoughtprovoking in high degree and will long remain a most valuable source book.

A. LANDSBOROUGH THOMSON

Tibet and Its Birds, by Charles Vaurie. Witherby, $£ 10.50$. Handbook of the Birds of India and Pakistan, Vols. 5 and 6, by Salim Ali and S. Dillon Ripley. OUP, f8 each.

Birds of Guatemala, by Hugh C. Land. Livingston, Wynnewood, Pa, \$10.00.

Although bird books continue to pour from the presses, there remains one huge blank, where we know almost nothing of the bird life today: China. It is therefore especially valuable to have a book on a small part of that huge and ornithologically almost unknown country, Tibet. Its avifauna is about as different from the only other part of China we know about, Hong Kong, as you would expect from the remoteness of the two. Charles Vaurie, of the American Museum of Natural History, is well known as the author of the standard work on the birds of the Palaearctic. The present volume is on similar lines, only in more detail, that is to say it covers only taxonomy and distribution, and not descriptions. The amount of distributional data given for Tibetan birds is, however, very detailed, and indeed almost exhaustive of what is known in the west. In addition there are a number of excellent introductory essays, which amount to a separate book on the geography of Tibet, the history of its ornithological exploration, and the more usual discussion of bird distribution and migration. All this is especially valuable to have about a part of the world that so few westerners are nowadays able to visit. The detailed gazetteer is particularly praiseworthy, and Arthur Singer's three colour plates illustrate some birds it would be hard to find depicted elsewhere.

The great Handbook of the Birds of India and Pakistan rolls on its majestic way. Shall we again, one wonders, see the like of this stupendous effort by two ornithologists to monograph the avifauna of a subcontinent? The Birds of the Western Palaearctic is assembling in the wings, but powered by a much larger team; the similar effort for North America has wilted after a single volume. The best news I have heard for a long time is that the remaining volumes of the Indian Handbook are now all in MS, and await only the ponderously creaking machine of modern publishing to process them.

The first four volumes have already been reviewed in ORYX (Dec. 1969, Sept. 1970, May 1971), and little more need be said but that these further two maintain the same high standard, both in text and illustrations, and that all those concerned with Indian ornithology are increasingly impatient to have the full set on their shelves. These two cover the larks, swallows, shrikes, orioles drongos, wood-swallows, starlings, mynahs, crows and waxwings (vol. 5), and the cuckoo-shrikes, minivets, ioras, bulbuls and babblers (vol. 6). Several of these families, notably the mynahs, minivets, bulbuls and babblers, are particularly characteristic of the Indian avifauna, and accurate and up-to-date information about them is correspondingly valuable.

Guatemala is one of the more favoured Central American countries so far as ornithology is concerned. The fact that so able an ornithologist as Jorge Ibarra lives and works there has meant a great encouragement for workers coming from abroad. One of these was the late Hugh Land, who provided 